\title{
Optical and photoluminescent properties of nanostructured hybrid films based on functional fullerenes and metal nanoparticles
}

\author{
N. Dmitruk ${ }^{1}$, O. Borkovskaya ${ }^{1}$, D. Naumenko ${ }^{1}$, N. Berezovska ${ }^{2}$, I. Dmitruk ${ }^{2}$, \\ V. Meza-Laguna ${ }^{3}$, E. Alvarez-Zauco ${ }^{3}$, E. Basiuk ${ }^{3,4}$ \\ ${ }^{1}$ Institute of Semiconductor Physics, NAS of Ukraine, 45, prospect Nauky, 03028 Kyiv, Ukraine \\ ${ }^{2}$ Taras Shevchenko Kyiv National University, Experimental Physics Department, \\ 64, Volodymyrs'ka str., 01601 Kyiv, Ukraine \\ ${ }^{3}$ Centro de Ciencias Aplicadas y Desarrollo Tecnológico, Universidad Nacional Autónoma de México, Circuito \\ Exterior C.U., 04510 México, D.F., Mexico \\ ${ }^{4}$ School of Materials Science and Engineering, University of New South Wales, Sydney 2052, Australia
}

\begin{abstract}
The chemically cross-linked $\mathrm{C}_{60}$ thin films, capable of binding $\mathrm{Ag}$ or $\mathrm{Au}$ nanoparticles, were prepared by the gas-phase treatment with diamine for one set of samples and dithiol for another one and decoration with $\mathrm{Ag}$ or $\mathrm{Au}$ nanoparticles, respectively. The optical and photoluminescent properties of the obtained nanostructured hybrid films in comparison with the undecorated films were studied. The low temperature photoluminescence (PL) spectra demonstrate significant changes of the band intensity and appearance of fine structure for bands connected with radiative transitions of self-trapped and localized excitons. The decoration of pristine and treated $\mathrm{C}_{60}$ films with Ag nanoparticles leads to a decrease of PL intensity and to slight bandgap reduction. These phenomena can be explained by the increase of the surface recombination velocity at the fullerene-nanoparticle interface. At the same time, the nanoparticles insignificantly decrease the transmittance of light into the fullerene and Si layers, and have almost no influence on photoelectric properties of metal/fullerene/Si barrier structures.
\end{abstract}

Keywords: fullerene $\mathrm{C}_{60}$, thin film, functionalization, octane-1,8-diamine, octane-1,8dithiol, silver nanoparticles, gold nanoparticles, optical, photoelectric.

Manuscript received 06.04.09; accepted for publication 14.05.09; published online 14.05.09.

\section{Introduction}

The development of different fullerene-based materials is stimulated by considerable potential for application in nanoelectronic devices. In particular, due to the special structural and chemical characteristics, $\mathrm{C}_{60}$ molecules in combination with metals are promising for creation of novel nanohybrid materials with unique catalytic, optical and photoelectric properties [1-3]. Thus, fullerene films provide a wide range of bonding sites which could be exploited as molecular templates. Different organic cross-linkers resulted to be very attractive to assemble nanoparticles in the formation of covalently linked superstructures. The cross-linking molecules with spacers of various lengths allows to control, to some extent, over interparticle spacing, and in its turn, the interparticle spacing influences the material properties such as conductivity. We applied the direct solvent-free functionalization of $\mathrm{C}_{60}$ films with aliphatic bifunctional amines and thiols, such as octane-1,8-diamine and octane-1,8-dithiol, to prepare covalently functionalized, cross-linked fullerene supports capable of strong binding and immobilization of noble metal (e.g., silver and gold) nanoparticles $[4,5]$. However, the properties of fullerene thin films depend considerably on the interface configuration, and the study of the absorption and luminescence behavior, charge transfer interactions of fullerene with the metal surface is of crucial importance.

In the present work, we report on a detailed study of optical and photoelectric properties of two series of pristine and chemically functionalized fullerene specimens based on the $\mathrm{C}_{60}$ films deposited on $n$-silicon substrates. This set of experimental methods allows to study both radiative and non-radiative recombination influences on photoresponse of fullerite films. The first series of samples consists of (i) pristine fullerene films $\left(\mathrm{C}_{60} / \mathrm{Si}\right)$, (ii) 1,8-diaminooctane-crosslinked $\mathrm{C}_{60}$ films $\left(\mathrm{C}_{60}-\mathrm{DA} / \mathrm{Si}\right)$, (iii) pristine films decorated with $\mathrm{Ag}$ 
nanoparticles $\left(\mathrm{C}_{60}-\mathrm{Ag} / \mathrm{Si}\right)$, and (iv) cross-linked films decorated with $\mathrm{Ag}$ nanoparticles $\left(\mathrm{C}_{60}-\mathrm{DA}-\mathrm{Ag} / \mathrm{Si}\right)$, and second series includes (i) pristine fullerene films $\left(\mathrm{C}_{60} / \mathrm{Si}\right)$, (ii) octane-1,8-dithiol-crosslinked $\mathrm{C}_{60}$ films $\left(\mathrm{C}_{60}-\mathrm{DT} / \mathrm{Si}\right)$, (iii) pristine films decorated with $\mathrm{Au}$ nanoparticles $\left(\mathrm{C}_{60}-\mathrm{Au} / \mathrm{Si}\right)$, and (iv) cross-linked films decorated with $\mathrm{Au}$ nanoparticles $\left(\mathrm{C}_{60}\right.$-DT-Au/Si).

\section{Experimental details}

$\mathrm{C}_{60}$ films were deposited on silicon Si (100) wafers by sublimation method. The deposition was performed in a vacuum chamber at the pressure of $6.2 \times 10^{-6}$ Torr, without heating the substrates. The average thickness of obtained film was about $100 \mathrm{~nm}$.

The gas-phase solvent-free procedure has been employed for functionalization of deposited fullerene films with aliphatic bifunctional amines and thiols, such as octane-1,8-diamine and octane-1,8-dithiol. The Ag and $\mathrm{Au}$ nanoparticle deposition is based on the reduction of $\mathrm{AgNO}_{3}$ or $\mathrm{HAuCl}_{4}$ with citric acid, respectively. The details concerning the samples preparation and analysis of their structure were reported formerly [4-6].

To characterize photoelectric properties of obtained fullerene/Si heterostructures, photodiodes were fabricated by evaporation of a semitransparent gold electrode layer (thickness of $22.7 \mathrm{~nm}$ ) through an opaque mask (opening diameter of $1.3 \mathrm{~mm}$ ) onto pristine and functionalized $\mathrm{C}_{60}$ films, and by making an ohmic contact to the rear side of Si substrate. These samples are referred to as $\operatorname{metal}(\mathrm{Au}) / \mathrm{C}_{60} / \mathrm{Si}$, metal $(\mathrm{Au}) / \mathrm{C}_{60}-\mathrm{DA} / \mathrm{Si}$, $\operatorname{metal}(\mathrm{Au}) / \mathrm{C}_{60}-\mathrm{Ag} / \mathrm{Si}$, and metal $(\mathrm{Au}) / \mathrm{C}_{60}-\mathrm{DA}-\mathrm{Ag} / \mathrm{Si}$.

\section{Results and discussion}

The investigation of structure and morphology of fullerene films before and after deposition of $\mathrm{Ag}$ nanoparticles was carried out by means of high-resolution transmission electron microscopy (HRTEM). As it is shown in Fig. 1a, pristine $\mathrm{C}_{60}$ film deposited onto a TEM grid exhibits mainly an amorphous structure, with the presence of dispersed crystalline regions. The morphology
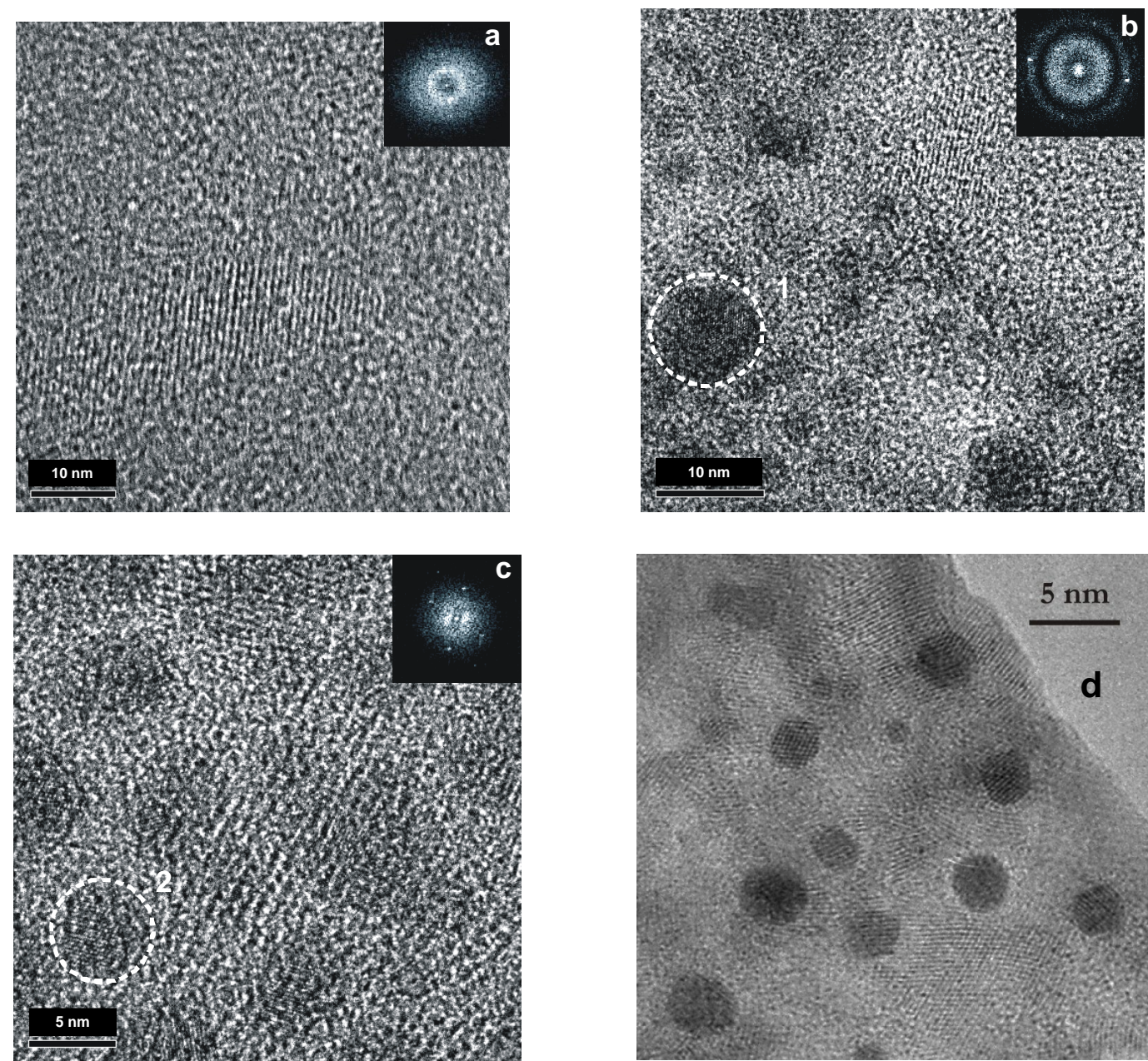

Fig. 1. HRTEM images of (a) pristine $\mathrm{C}_{60}$ before the deposition of silver nanoparticles, Ag nanoparticles deposited onto (b) pristine and (c) 1,8-diaminooctane-functionalized $\mathrm{C}_{60}$. Insets show selected area electron diffraction patterns for (a) pristine $\mathrm{C}_{60}$ and (b, c) Ag nanoparticles marked with numbered white circles; (d) HRTEM images of 1,8-dithioloctane-functionalized $\mathrm{C}_{60}$ with $\mathrm{Au}$ nanoparticles. 
of silver nanoparticles deposited onto the TEM gridsupported pristine and diamine-functionalized $\mathrm{C}_{60}$ films is exemplified in Fig. 1b,c, respectively, where the insets correspond to electron diffraction patterns of the particles marked with white circles. Four diffraction planes, namely (111), (200), (222), and (311), were identified in the case of $\mathrm{Ag}$ on pristine $\mathrm{C}_{60}$, whereas only (111) and (222) planes were clearly observed for typical Ag nanoparticles on the diamine-functionalized $\mathrm{C}_{60}$. The $\mathrm{Ag}$ particle size dispersion was narrower, as well as the coverage was more uniform, in the case of 1,8-diaminooctanefunctionalized $\mathrm{C}_{60}$, as compared to pristine fullerene. The particles of about $5 \mathrm{~nm}$ in diameter were typically observed on the functionalized $\mathrm{C}_{60}$, whereas they had much more variable sizes when deposited onto pristine $\mathrm{C}_{60}$. For octane-1,8-dithiol-functionalized films (Fig. 1d), the Au particle sizes exhibited a narrow dispersion. The particles of about $3 \mathrm{~nm}$ in diameter were commonly observed on the dithiol-functionalized $\mathrm{C}_{60}$ films.

For optical characterization of investigated structures, the reflectance spectra were measured in the energy range of $h v=1.1-3.1 \mathrm{eV}$ at variable angles of incidence of $p$ - and $s$-polarized light. The fullerene layer thickness value and its optical parameters (refractive index $n$, and extinction coefficient $k$ at complex refractive index $\check{n}=n-i k$ ) were determined by fitting of experimental dependences with theoretical ones, calculated within the framework of a one-layer model for pristine or functionalized $\mathrm{C}_{60}$ films. To confirm these results, the ellipsometric measurements were performed using a Woollam M2000DI rotating compensator ellipsometer in the spectral range of $1.55-5 \mathrm{eV}$, at angles of incidence of $45^{\circ}, 60^{\circ}, 65^{\circ}$, and $75^{\circ}$ for $\mathrm{C}_{60}$-DT-Au/Si structure (Fig. 2). The obtained parameters allowed to calculate the spectral dependences of the absorption coefficient $(\alpha=4 \pi k / \lambda)$ (Figs 3 and 4$)$ and the spectra of light transmittance into $\mathrm{Si}$ substrate through $\mathrm{Au}, \mathrm{C}_{60}$ and $\mathrm{Au} / \mathrm{C}_{60}$ layers, which are used later for calculating the internal quantum efficiency spectra.

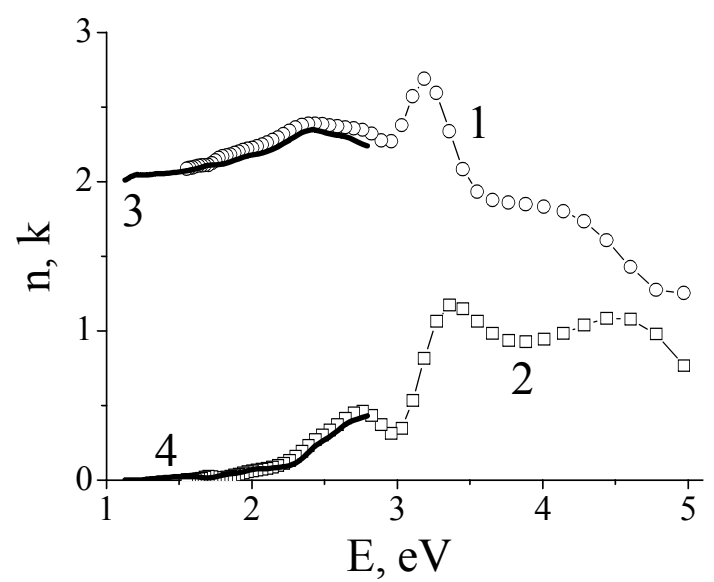

Fig. 2. The dispersion of refractive index $n(1,3)$ and extinction coefficient $k(2,4)$ for $\mathrm{C}_{60}$-DT-Au film on $\mathrm{Si}$ substrate. The results obtained from the ellipsometric measurements $(1,2)$, and from reflectance measurements $(3,4)$.
Photoluminescence (PL) spectra were studied with a grating monochromator MDR-3 at room and low (77 and $2 \mathrm{~K}$ ) temperatures under $\mathrm{Ar}$ ion laser $(488 \mathrm{~nm})$ excitation.

At room temperature, for samples of series 1 we have observed the wide structureless asymmetric PL band with maximum in the vicinity of $1.5 \mathrm{eV}$ (Fig. 3). The intensity of PL spectrum of diamine-functionalized film was higher than for pristine fullerene film. The intensity of PL spectra of pristine and cross-linked films decorated with Ag nanoparticles depends on the place of the excitation spot on the sample. As for series 2, the PL spectra demonstrated two strongly overlapped bands with pronounced maxima at 1.51 and $1.67 \mathrm{eV}$ (according to the multi-peak analysis) (Fig. 4).

The PL spectra of samples of series 1 at $77 \mathrm{~K}$ are shown in Fig. 5. Experimental PL spectra have been approximated with a sum of Gaussian bands. Such fitting allows to determine the spectral position $\left(x_{i}\right)$ of the bands more precisely (Table). The band positions are in agreement with the values reported for $\mathrm{C}_{60}$ solid films measured at $100 \mathrm{~K}$ [7] and $80 \mathrm{~K}$ [8]. A slight red shift of PL bands observed for $\mathrm{C}_{60}-\mathrm{DA} / \mathrm{Si}$ film relative to the pristine one is characteristic for photopolymerized $\mathrm{C}_{60}$ solid films [7,8] and is consistent with our earlier results for photopolymerized and chemically crosslinked fullerenes [9]. Chemical cross-linking of $\mathrm{C}_{60}$ molecules removes the degeneracies of the electronic energy levels in the $\mathrm{C}_{60}$ monomers. The pristine fullerene films are typically composed of well-shaped $\mathrm{C}_{60}$ clusters of the approximately $50 \mathrm{~nm}$ average diameter. Their edges became notably diffuse after the modification with diamine [4]. These changes can be explained by the formation of covalent cross-links between neighboring fullerene molecules and clusters: since the diamine linkers are relatively big and cannot fit the spaces between $\mathrm{C}_{60}$ molecules, the latter had to reaccommodate, thus making the film less dense and ordered.

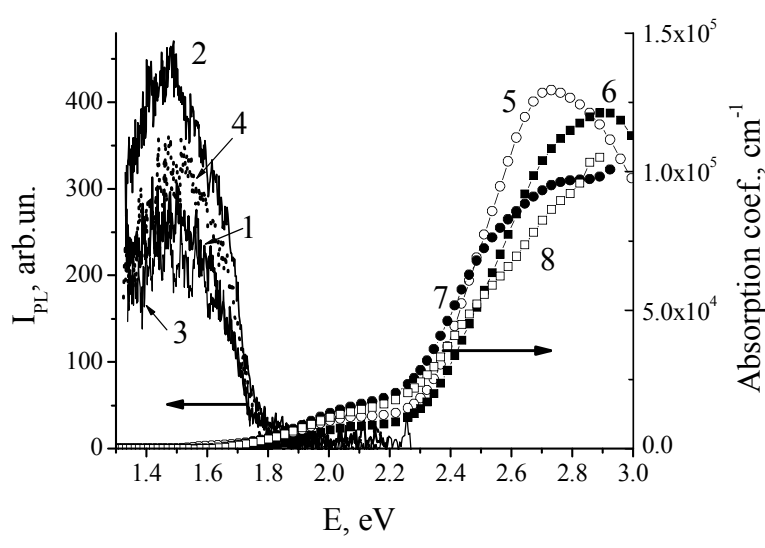

Fig. 3. The photoluminescence (1-4) and absorption coefficient (5-8) spectra for structures of series 1: pristine $\mathrm{C}_{60}$ layer $(1,5)$, $\mathrm{C}_{60}$-DA $(2,6), \mathrm{C}_{60}-\mathrm{Ag}(3,7)$ and $\mathrm{C}_{60}$-DA-Ag $(4,8) . \lambda_{\text {excPL }}=$ $488.0 \mathrm{~nm}, T=300 \mathrm{~K}$. 


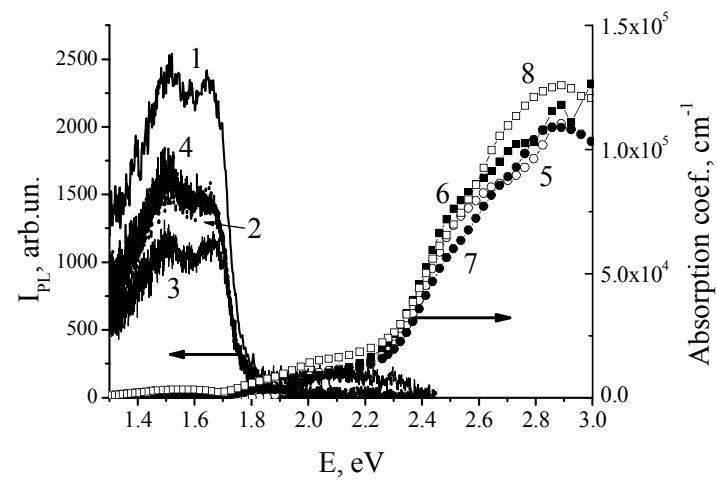

Fig. 4. The photoluminescence (1-4) and absorption coefficient $(5-8)$ spectra for structures of series 2 : pristine $\mathrm{C}_{60}$ layer $(1,5)$, $\mathrm{C}_{60}$-DT $(2,6), \mathrm{C}_{60}-\mathrm{Au}(3,7)$ and $\mathrm{C}_{60}$-DT-Au $(4,8) . \lambda_{\text {excPL }}=$ $488.0 \mathrm{~nm}, T=300 \mathrm{~K}$.

Table. The spectral positions $\left(x_{i}\right)$ of Gaussian bands in PL spectra of pristine and functionalized fullerene films, with and without deposited metal nanoparticles.

\begin{tabular}{|c|c|c|c|c|}
\hline \multirow[t]{2}{*}{ Band } & $\mathrm{C}_{60} / \mathrm{Si}$ & $\mathrm{C}_{60}-\mathrm{DA} / \mathrm{Si}$ & $\mathrm{C}_{60}-\mathrm{Ag} / \mathrm{Si}$ & $\begin{array}{c}\mathrm{C}_{60}-\mathrm{DA}- \\
\mathrm{Ag} / \mathrm{Si}\end{array}$ \\
\hline & $x_{1}, \mathrm{eV}$ & $x_{2}, \mathrm{eV}$ & $x_{3}, \mathrm{eV}$ & $x_{4}, \mathrm{eV}$ \\
\hline \multicolumn{5}{|c|}{ Series $1, T=77 \mathrm{~K}$} \\
\hline I & 1.696 & 1.695 & 1.690 & 1.689 \\
\hline II & 1.659 & 1.658 & 1.651 & 1.652 \\
\hline III & 1.615 & 1.619 & 1.620 & 1.617 \\
\hline IV & 1.570 & 1.574 & 1.584 & 1.579 \\
\hline V & 1.517 & 1.517 & 1.531 & 1.523 \\
\hline VI & 1.471 & 1.471 & 1.488 & 1.482 \\
\hline VII & 1.418 & 1.418 & 1.436 & 1.431 \\
\hline VIII & 1.358 & 1.360 & 1.379 & 1.374 \\
\hline \multicolumn{5}{|c|}{ Series $1, T=2 \mathrm{~K}$} \\
\hline I & 1.695 & 1.704 & 1.704 & 1.699 \\
\hline II & 1.658 & 1.685 & 1.679 & 1.658 \\
\hline III & 1.621 & 1.617 & 1.609 & 1.603 \\
\hline IV & 1.580 & 1.521 & 1.522 & 1.533 \\
\hline V & 1.516 & 1.480 & 1.456 & 1.483 \\
\hline VI & 1.454 & 1.440 & 1.402 & 1.430 \\
\hline VII & 1.398 & 1.386 & 1.348 & 1.359 \\
\hline VIII & 1.326 & 1.319 & 1.300 & 1.300 \\
\hline \multirow[t]{2}{*}{ Band } & $\mathrm{C}_{60} / \mathrm{Si}$ & $\mathrm{C}_{60}-\mathrm{DT} / \mathrm{Si}$ & $\mathrm{C}_{60}-\mathrm{Au} / \mathrm{Si}$ & $\begin{array}{c}\mathrm{C}_{60}-\mathrm{DT}- \\
\mathrm{Au} / \mathrm{Si}\end{array}$ \\
\hline & $x_{1}, \mathrm{eV}$ & $x_{2}, \mathrm{eV}$ & $x_{3}, \mathrm{eV}$ & $x_{4}, \mathrm{eV}$ \\
\hline \multicolumn{5}{|c|}{ Series $2, T=77 \mathrm{~K}$} \\
\hline I & 1.711 & 1.699 & 1.702 & 1.701 \\
\hline II & 1.682 & 1.670 & 1.665 & 1.668 \\
\hline III & 1.638 & 1.629 & 1.625 & 1.601 \\
\hline IV & 1.591 & 1.585 & 1.585 & 1.539 \\
\hline V & 1.529 & 1.523 & 1.532 & 1.501 \\
\hline VI & 1.491 & 1.487 & 1.486 & 1.444 \\
\hline VII & 1.429 & 1.436 & 1.432 & 1.372 \\
\hline VIII & 1.331 & 1.331 & 1.330 & 1.300 \\
\hline \multicolumn{5}{|c|}{ Series $2, T=2 \mathrm{~K}$} \\
\hline I & 1.708 & 1.705 & 1.705 & 1.702 \\
\hline II & 1.678 & 1.675 & 1.667 & 1.669 \\
\hline III & 1.631 & 1.625 & 1.623 & 1.610 \\
\hline IV & 1.587 & 1.583 & 1.587 & 1.554 \\
\hline V & 1.532 & 1.528 & 1.534 & 1.504 \\
\hline VI & 1.482 & 1.487 & 1.487 & 1.442 \\
\hline VII & 1.419 & 1.421 & 1.422 & 1.365 \\
\hline VIII & 1.336 & 1.336 & 1.335 & 1.300 \\
\hline
\end{tabular}

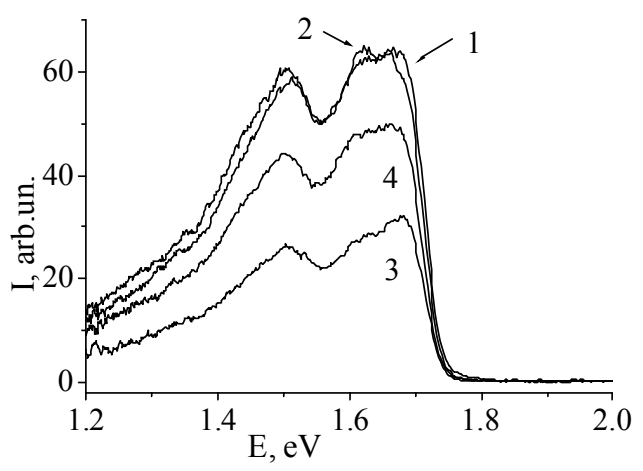

Fig. 5. Photoluminescence spectra of $\mathrm{C}_{60} / \mathrm{Si}(1), \mathrm{C}_{60}-\mathrm{DA} / \mathrm{Si}$ (2), $\mathrm{C}_{60}-\mathrm{Ag} / \mathrm{Si}(3)$ and $\mathrm{C}_{60}-\mathrm{DA}-\mathrm{Ag} / \mathrm{Si}(4), \lambda_{\mathrm{exc}}=488.0 \mathrm{~nm}, \quad T=$ $77 \mathrm{~K}$.

The decoration of fullerene films with $\mathrm{Ag}$ nanoparticles results in an additional red shift of PL bands (see Table), which correlates with the decrease of the band gap values. Similar effect was also reported by other authors $[10,11]$. Besides, the PL band intensities for the functionalized $\mathrm{C}_{60}$ samples are redistributed. The diamine treatment increases intensities of the bands below $1.689 \mathrm{eV}$, whereas the $\mathrm{Ag}$ decoration decreases them. It should be mentioned that the interaction of $\mathrm{Ag}$ core with pristine $\mathrm{C}_{60}$ molecules, which do not have nitrogen donor atoms capable of stable silver coordination, is weaker as compared to the diaminefunctionalized fullerene. In the latter case, the newly formed $\mathrm{Ag}$ nanoparticles remain strongly coordination bound to the $\mathrm{NH}$ bridges (and to the existing unreacted $\mathrm{NH}_{2}$ groups), which are separated by a considerable distance from each other, and thus immobilized. On the contrary, the silver core keeps their mobility on pristine $\mathrm{C}_{60}$, and therefore can undergo gradual coalescence increasing their size and forming twins. The PL band at $1.689 \mathrm{eV}$ (Fig. 5) can be attributed to the radiative recombination of self-trapped polaron excitons [12]. This exciton can be considered as a Frenkel exciton trapped by lattice deformation. Bands at lower energies are due to the emission from the so-called X traps [13], or defects presumably associated with the grain boundaries [8]. Likewise the case of photopolymerized $\mathrm{C}_{60}$ solid films $[7,8,14]$, the observed changes of PL band position and intensity due to the 1,8-diaminooctane functionalization can be explained by a transformation of shallow traps into deeper traps caused by the perturbation of icosahedral shell symmetry of $\mathrm{C}_{60}$ molecules and activation of new vibrational and electronic states in the cross-linked films. The decrease of all PL bands intensities after the deposition of $\mathrm{Ag}$ nanoparticles can be explained by an increase of the non-radiative surface recombination velocity at the fullerene-Ag interface.

The main features of PL spectra of the samples of series 2 are similar to those in the spectra of series 1 (Fig. 6). However, the intensity of PL spectrum of dithiol-functionalized $\mathrm{C}_{60}$ film is considerably lower in comparison with the pristine $\mathrm{C}_{60}$ film spectrum. It is the 


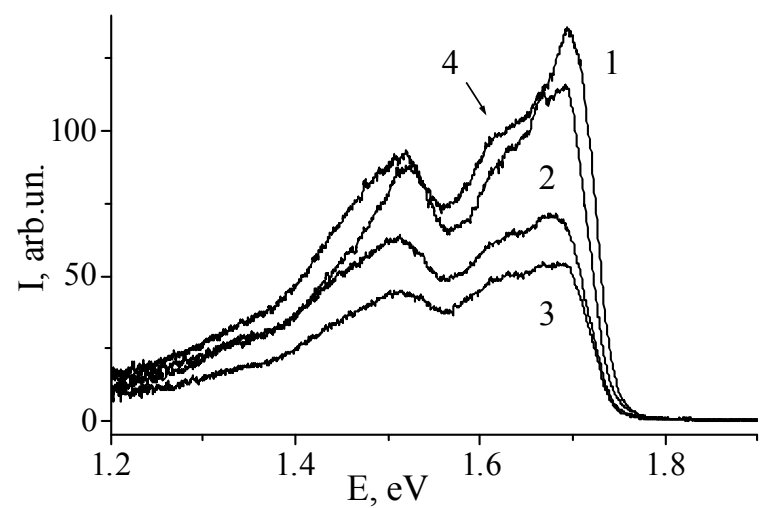

Fig. 6. Photoluminescence spectra of $\mathrm{C}_{60} / \mathrm{Si}(1), \mathrm{C}_{60^{-}}$ $\mathrm{DT} / \mathrm{Si}(2), \quad \mathrm{C}_{60}-\mathrm{Au} / \mathrm{Si}(3)$ and $\mathrm{C}_{60}-\mathrm{DT}-\mathrm{Au} / \mathrm{Si}(4), \quad \lambda_{\mathrm{exc}}=$ $488.0 \mathrm{~nm}, T=77 \mathrm{~K}$.

known fact that the considerable difference in the reactivity of amines and thiols might influence the crosslinking reaction.

The blueshift has been observed for the PL spectra of both series by lowering the temperature from the room one to $77 \mathrm{~K}$. A further temperature decrease did not induce any distinguishable band shift.

The PL spectra of both series at $2 \mathrm{~K}$ demonstrate the clearly defined structure (Figs 7,8). It should be mentioned the considerable increase of intensity of PL spectra of functionalized and Au-decorated fullerene films in comparison with the intensity of pristine film emission (see Fig. 8). Another peculiarity of the PL spectra of series 2 is the appearance of the band at $1.78 \mathrm{eV}$. The nature of this band is not quite apparent. Likely, it is caused by some uncontrolled impurities (for example, oxygen).

In the low energy range of PL spectra of both series, the band close to $1.52 \mathrm{eV}$ has been carefully observed. The energetic separation with respect to the exciton state at $1.7 \mathrm{eV}$ is about $180 \mathrm{meV}$. This band can be assigned to the phonon replica involving the high frequency Raman-active mode $\mathrm{A}_{g}$ at $1469 \mathrm{~cm}^{-1}$ $(182 \mathrm{meV})$. The Raman spectrum of diamine-

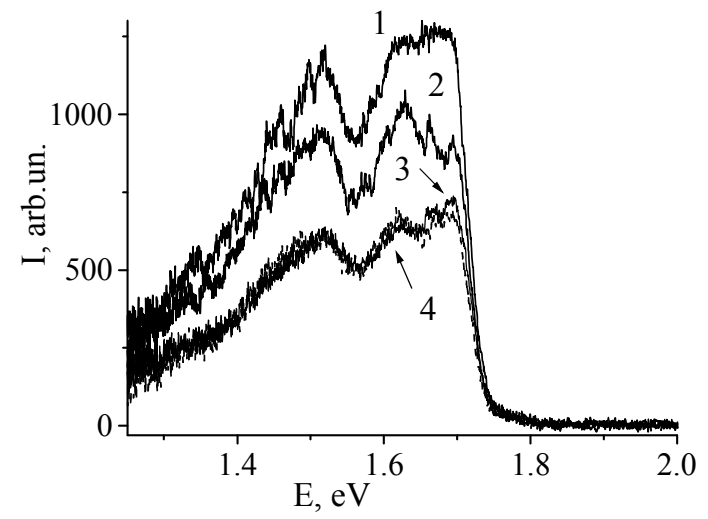

Fig. 7. Photoluminescence spectra of $\mathrm{C}_{60} / \mathrm{Si}(1), \mathrm{C}_{60^{-}}$ $\mathrm{DA} / \mathrm{Si}(2), \mathrm{C}_{60}-\mathrm{Ag} / \mathrm{Si}(3)$ and $\mathrm{C}_{60}-\mathrm{DA}-\mathrm{Ag} / \mathrm{Si}(4), \quad \lambda_{\mathrm{exc}}=$ $488.0 \mathrm{~nm}, T=2 \mathrm{~K}$.

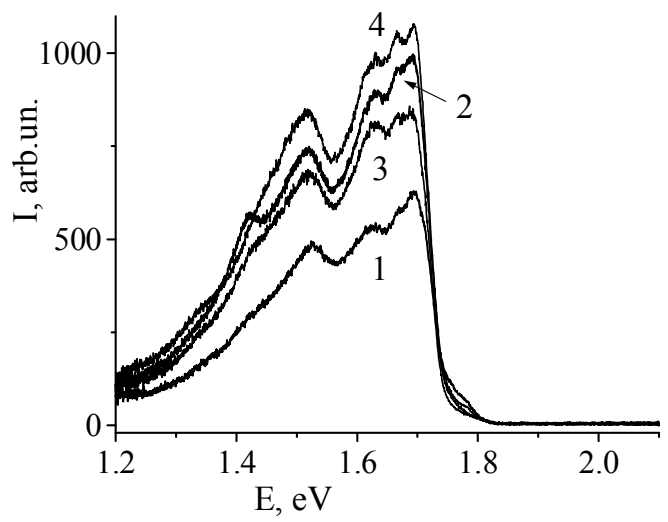

Fig. 8. Photoluminescence spectra of $\mathrm{C}_{60} / \mathrm{Si}(1), \mathrm{C}_{60^{-}}$ $\mathrm{DT} / \mathrm{Si}(2), \quad \mathrm{C}_{60}-\mathrm{Au} / \mathrm{Si}(3)$ and $\mathrm{C}_{60}-\mathrm{DT}-\mathrm{Au} / \mathrm{Si}(4), \quad \lambda_{\mathrm{exc}}=$ $488.0 \mathrm{~nm}, T=2 \mathrm{~K}$.

functionalized $\mathrm{C}_{60}$ film, obtained earlier [4], showed a decrease of the intensity for the main intramolecular Raman-active modes due to changes in the hybridization state of the diamine-bond carbon atoms in $\mathrm{C}_{60}$.

An example of the spectra of the short-circuit photocurrent, expressed as the external quantum efficiency $Q_{\text {ext }}$ (that is, the number of photocurrent carriers generated in metal( $\mathrm{Au}) /$ fullerene/Si structure by one photon of the incident light), for the photodiodes including $\mathrm{C}_{60}$ layers of the series 1 are shown in Fig. 9. The obtained experimental results can be summarized as follows: (i) the highest photocurrent values were obtained for metal $(\mathrm{Au}) / \mathrm{C}_{60} / \mathrm{Si}$; (ii) the 1,8-diaminooctane functionalization decreases the photocurrent values by an order of magnitude; (iii) the $\mathrm{Ag}$ decoration of fullerene films (especially of pristine $\mathrm{C}_{60} / \mathrm{Si}$ ) also decreases the photocurrent value. To interpret this behavior, the light absorption by the $\mathrm{Au}$ and $\mathrm{C}_{60}$ layers must be taken into account. The spectra of the internal quantum efficiency $Q_{\text {int }}$ (Fig. 10) (that is, the number of current carriers generated by one photon of the light transmitted into $\mathrm{Si}$ ) were calculated from the experimental $Q_{\text {ext }}$ spectra (Fig. 9). Namely, the $Q_{\text {ext }}$ values were divided by the corresponding values of light transmitted through metal $(\mathrm{Au}) /$ fullerene layers. The photocurrent spectra of the Ag-decorated films are similar in general to ones of the silver-free pristine and diamine-functionalized samples (see curves 1 and 3,2 and 4 in Fig. 9), but the $Q_{\text {int }}$ values for the Ag-decorated samples are considerably lower within the entire spectral range. These calculated $Q_{\text {int }}$ spectra take into account the contribution of photocurrent generated in the silicon substrate (including photocurrent, generated outside the diode area). Therefore, the apparent $Q_{\text {int }}$ value can be greater than unity. At the same time, the photocurrent generated in the fullerene layer is multiplied by a factor of $T_{1} / T_{2}$ (that is, the ratio of the transmittance $T_{1}$ through the Au electrode layer into fullerene to transmittance $T_{2}$ through metal $(\mathrm{Au}) /$ fullerene layers into $\mathrm{Si}$ ). Therefore, the contribution of photocurrent generated in the fullerene layer becomes more obvious. 


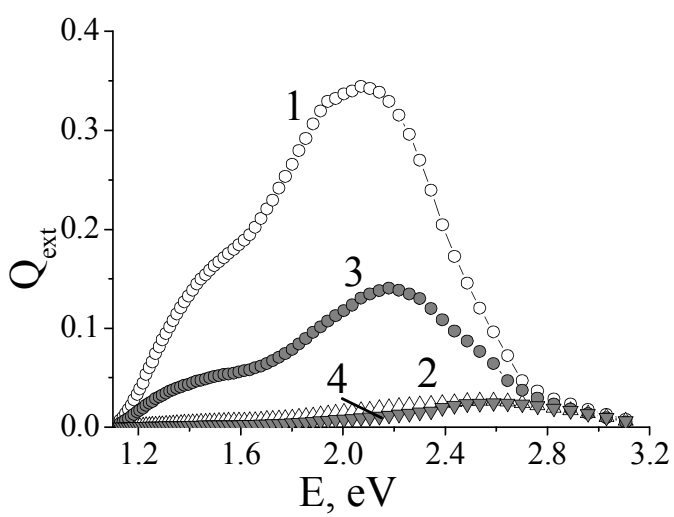

Fig. 9. Spectra of external quantum efficiency for photodiodes $\operatorname{metal}(\mathrm{Au}) / \mathrm{C}_{60} / \mathrm{Si}(1), \operatorname{metal}(\mathrm{Au}) / \mathrm{C}_{60^{-}}-\mathrm{DA} / \mathrm{Si}(2), \operatorname{metal}(\mathrm{Au}) / \mathrm{C}_{60^{-}}$ $\mathrm{Ag} / \mathrm{Si}(3)$ and metal( $\mathrm{Au}) / \mathrm{C}_{60}-\mathrm{DA}-\mathrm{Ag} / \mathrm{Si}(4)$.

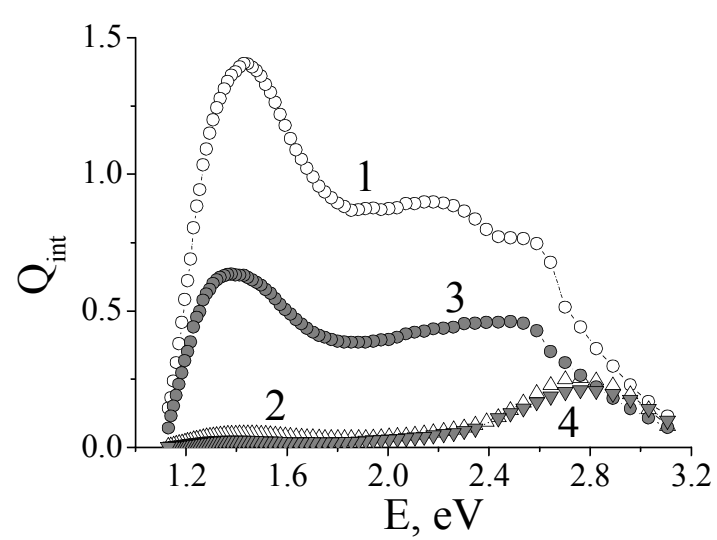

Fig. 10. Spectra of internal quantum efficiency for photodiodes $\operatorname{metal}(\mathrm{Au}) / \mathrm{C}_{60} / \mathrm{Si}(1), \operatorname{metal}(\mathrm{Au}) / \mathrm{C}_{60^{-}} \mathrm{DA} / \mathrm{Si}(2), \operatorname{metal}(\mathrm{Au}) / \mathrm{C}_{60^{-}}$ $\mathrm{Ag} / \mathrm{Si}(3)$ and $\operatorname{metal}(\mathrm{Au}) / \mathrm{C}_{60}-\mathrm{DA}-\mathrm{Ag} / \mathrm{Si}(4)$.

Since the main decrease in $Q_{\text {int }}$ for $\operatorname{metal}(\mathrm{Au}) / \mathrm{C}_{60^{-}}$ $\mathrm{DA} / \mathrm{Si}$ and metal $(\mathrm{Au}) / \mathrm{C}_{60}-\mathrm{DA}-\mathrm{Ag} / \mathrm{Si}$ is observed within the spectral range of photocurrent generation in the silicon substrate (at energies of $<2.5 \mathrm{eV}$ ), this implies a decreased current collection of photocurrent carriers generated in Si. The reasonable causes are the changes in both barrier properties of the fullerene $/ n$-Si heterostructure and their recombination characteristics after the 1,8-diaminooctane functionalization. An additional cause of the photocurrent decrease is a certain increase of series resistance of fullerite layer obtained from the analysis of the dark current-voltage characteristics for metal $(\mathrm{Au}) / \mathrm{C}_{60}-\mathrm{DA} / \mathrm{Si}$ and metal $(\mathrm{Au}) / \mathrm{C}_{60}-\mathrm{DA}-\mathrm{Ag} / \mathrm{Si}$ structures as compared to $\operatorname{metal}(\mathrm{Au}) / \mathrm{C}_{60} / \mathrm{Si}$ and $\operatorname{metal}(\mathrm{Au}) / \mathrm{C}_{60}-\mathrm{Ag} / \mathrm{Si}$, i.e. without diamine treatment. As a whole, the $\mathrm{Ag}$ nanoparticle deposition only slightly decreases the light transmittance into the fullerene and Si layers, and has almost no influence on the electrical and photoelectric properties of metal $(\mathrm{Au}) /$ fullerene/Si barrier structures. The main influence on the photocurrent is caused by non-radiative recombination in the structure.

\section{Conclusions}

The method of solvent-free functionalization with 1,8 diaminooctane or octane-1,8-dithiol was employed for the covalent cross-linking of $\mathrm{C}_{60}$ thin films capable of binding $\mathrm{Ag}$ or $\mathrm{Au}$ nanoparticles, respectively. Photoluminescence spectra of the studied nanoparticle hybrid structures have been measured within the wide temperature range (from room temperature down to $2 \mathrm{~K}$ ). The fine structure of obtained PL spectra is mainly attributed to the recombination of self-trapped polaron excitons and its phonon replicas. The low energy bands are caused by emission from the so-called $\mathrm{X}$ traps appearing due to chemical impurities and defects. The changes of recombination properties of fullerene films in consequence of the process of chemical functionalization and decoration with nanoparticles determine the observed changes of PL intensity. The fabricated photodiodes with a semitransparent $\mathrm{Au}$ electrode layer onto pristine and functionalized, Ag-decorated and undecorated $\mathrm{C}_{60}$ films on $\mathrm{n}$-Si substrate showed a significant decrease of the photocurrent value and some increase of dark resistance for the diaminefunctionalized films. These phenomena can be attributed to an insulating effect of 1,8-diaminooctane molecules incorporated between $\mathrm{C}_{60}$ cages, which causes a slight change of barrier properties of fullerene $/ n-\mathrm{Si}$ heterostructure and, on the other hand, a considerable increase of the fullerene $/ n$-Si interface non-radiative recombination velocity.

\section{References}

1. M.S. Dresselhaus, G. Dresselhaus, A.M. Rao, and P.C. Eklund, Optical properties of $\mathrm{C}_{60}$ and related materials // Synth. Metals 78 (3), p. 313-325 (1996).

2. M.D.R. Taylor, P. Moriarty, B.N. Cotier, M.J. Butcher, P.H. Beton, and V.R. Dhanak, Doping of covalently bound fullerene monolayers: Ag clusters on $\mathrm{C}_{60} / \mathrm{Si}(111) / /$ Appl. Phys. Lett. 77(8), p. 11441146 (2000).

3. P.K. Sudeep, D.I. Ipe, K.G. Thomas, M.V. George, S. Barazzouk, S. Hotchandani, and P.V. Kumat, Fullerene-Functionalized Gold Nanoparticles. A self-assembled photoactive antenna-metal nanocore assembly // Nano Lett. 2(1), p. 29-35 (2002).

4. V. Meza-Laguna, E.V. Basiuk (GolovatayaDzhymbeeva), E. Alvarez-Zauco, D. AcostaNajarro, and V.A. Basiuk, Cross-linking of $\mathrm{C}_{60}$ films with 1,8-diaminooctane and further decoration with silver nanoparticles // J. Nanosci. Nanotechnol. 7(10), p. 3563-3571 (2007).

5. V. Meza-Laguna, E.V. Basiuk (GolovatayaDzhymbeeva), E. Alvarez-Zauco, T.Yu. Gromovoy, O. Amelines-Sarria, M. Bassiouk, I. Puente-Lee, and V.A. Basiuk, Fullerene $\mathrm{C}_{60}$ films cross-linked with octane-1,8-dithiol: preparation, characterization and the use as template for chemical deposition of gold 
nanoparticles // J. Nanosci. Nanotechnol. 8(8), p. 3828-3837 (2008).

6. N.L. Dmitruk, O.Yu. Borkovskaya, S.V. Mamykin, D.O. Naumenko, V. Meza-Laguna, E. AlvarezZauco, and E.V. Basiuk, Fullerene C60-silver nanoparticles hybrid structures: Optical and photoelectric characterization // J. Nanosci. Nanotechnol. 8(11), p. 5958-5965 (2008).

7. U.D. Venkateswaran, D. Sanzi, A.M. Rao, P.C. Eklund, L. Marques, J.-L. Hodeau, and M. Nuñez-Regueiro, Temperature dependence of the photoluminescence in polymeric solid $\mathrm{C}_{60} / /$ Phys. Rev. B 57(6), p. R3193-R3196 (1998).

8. Y. Wang, J.M. Holden, A.M. Rao, P.C. Eklund, U.D. Venkateswaran, DeLyle Estwood, R.L. Lidberg, G. Dresselhaus, and M.S. Dresselhaus, Optical absorption and photoluminescence in pristine and photopolymerized $\mathrm{C}_{60}$ solid films // Phys. Rev. B 51(7), p. 4547-4556 (1995).

9. N.L. Dmitruk, O.Yu. Borkovskaya, I.B. Mamontova, O.S. Kondratenko, D.O. Naumenko, E.V. Basiuk (Golovataya-Dzhymbeeva), and E. AlvarezZauco, Optical and electrical characterization of chemically and photopolymerized $\mathrm{C}_{60}$ thin films on silicon substrates // Thin Solid Films 515, p. 77167720 (2007)

10. R.W. Lof, M.A. van Veenendaal, B. Koopmans, H.T. Jonkman, and G.A. Sawatzky, Band gap, excitons, and Coulomb interaction in solid $\mathrm{C}_{60} / /$ Phys. Rev. Lett. 68, p. 3924-3927 (1992).

11. B. Mishori, Y. Shapira, A. Belu-Marian, M. Manciu, and A. Devenyi, Studies of $\mathrm{C}_{60}$ thin films using surface photovoltage spectroscopy // Chem. Phys. Lett. 264, p. 163-167 (1997).

12. M. Matus, H. Kuzmany, E. Sohmen, Self-trapped polaron exciton in neutral fullerene $\mathrm{C}_{60} / /$ Phys. Rev. Lett. 68(18), p. 2822-2825 (1992).

13. W. Guss, J. Feldmann, E.O. Göbel, C. Taliani, H. Mohn, W. Müller, P. Häussler, and H.-U. ter Meer, Fluorescence from $\mathrm{X}$ traps in $\mathrm{C}_{60}$ single crystals // Phys. Rev. Lett. 72(16), p. 2644-2647 (1994).

14. V.A. Karachevtsev, A.Y. Glamazda, V.A. Pashinskaya, A.V. Peschanskii, A.M. Plokhotnichenko, and V.I. Fomin, Luminescence and Raman scattering of nonpolymerized and photopolymerized fullerene films at 297 and $5 \mathrm{~K} / / \mathrm{J}$. Low Temp. Phys. 33, p. $704-709$ (2007). 